\title{
Evaluation Of The Success Of A Master Of Business Administration Program: A Case Study Of Thammasat Business School
}

Sripen Supmonchai, Thammasat University, Thailand

Nopadol Rompho, Thammasat University, Thailand

\begin{abstract}
The objective of this study is to investigate the usefulness of knowledge gained from an MBA program based on the opinion of current MBA students. It was found that students believe the number of credits and the duration of study are appropriate. By using factor analysis on the usefulness of each MBA subject, five factors were found, all of which can explain overall usefulness by $50 \%\left(R^{2}=50 \%\right)$. Those factors, ranked by effect, are the group of subjects related to 1) strategies and business model, 2) economics and finance, 3) sustainable development, 4) management analytical tools, and 5) relationship within organization. The findings from this research can be used to improve MBA curricula in the future.
\end{abstract}

Keywords: Master of Business Administration; Evaluation; Thailand

\section{IMPORTANCE OF MBA PROGRAMS}

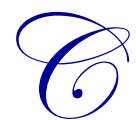

urrently, postgraduate education is vitally important and increasingly essential when working in an everchanging environment. This can be seen in the large number of leading institutions where most employees have completed postgraduate degrees. The increasing demand for postgraduate education has led educational institutions, especially universities, to develop programs to support this rising demand in order to produce qualified graduates to take part in the development of the country.

The MBA has been accepted as the most well-known program as a result of two main factors: first, MBA programs focus on improving management skills, which are necessary for all professions, including engineering, medicine, and finance. People employed in these professions are interested in enhancing their knowledge and in developing into good managers. The second factor that makes MBAs so popular is that these programs do not require a specific type of bachelor's degree, in contrast to other master's degrees. Instead, MBA programs are open to anyone with a bachelor's degree in any field. There is no restriction on the educational background of the candidates.

A number of universities have started to offer MBA programs to support the increasing demand, but this trend is increasingly giving rise to concerns about the teaching quality of these MBA courses. Many educational institutions seem to be focused on quantity, and this may have an impact on quality. Further, many of these programs accept as many students as possible without considering their own capacity. This can lead to what is called "Fully Paid, Graduation Guaranteed," which is definitely not a good thing for the country's education system.

One factor that affects student competence is the curriculum. Some institutions might argue that their current curricula comply with the regulations set out by the Office of the Higher Education Commission (OHEC). This is true; otherwise, they would not be approved. However, simply conforming to rules (such as having an appropriate number of instructors or an appropriate number of credits in core and elective subjects) does not assure that the program is of high quality. The current quality assessment carried out by OHEC only checks whether programs comply with regulations, not whether students are obtaining real benefits from the programs. Even though many universities have done research on employer satisfaction, it needs to be recognized that employer satisfaction 
may not indicate the success or failure of the programs, as there are other external factors that influence employer satisfaction.

In addition, the economic difficulties now being faced by many countries has had a pass-through effect on business graduate programs. According to a study by the Graduate Management Admission Council published in Business Week Magazine (VanderMey, 2009), it was found that in the year 2009, about 25\% of employers would not hire MBA graduates, far higher than the $17 \%$ in 2008. It was also found that the average salary level of MBA graduates in 2009 was at best equal to, or at worst lower than, the level in the previous year. Therefore, it is very clear that for universities to offer successful MBA programs, they must provide curricula that fulfill the needs of both employers and students.

With this in mind, this research will focus on developing an effective evaluation framework for MBA programs by looking at what approaches universities can use to evaluate and improve their curricula.

\section{DEVELOPMENT OF AN MBA PROGRAM}

The Master of Business Administration Program, widely known as "MBA," is one of the world's most well-known courses. Recently, however, MBA programs have been criticized because it is not clear what benefits students receive from them. The most essential benefit for an MBA graduate is the ability to apply the knowledge they gain from the MBA to their work and thus advance their career prospects. Surprisingly, however, it has been found that graduates do not really gain much from applying their knowledge to their work and the knowledge has little effect on their salaries or career advancement (Pfeffer and Fong, 2002). At the same time, studies by several researchers showed the opposite: when they calculated the return on investment of MBAs, they found that students received a high return. These studies showed that even though the value of MBAs has continuously declined recently, they are still worth the investment. The research has also shown that the need for MBA graduates remains high, especially when economies improve (Carmichael and Sutherland, 2005; Connolly, 2003; Van Auken and Chrysler, 2005). It is the contention of these researchers that assessment of the value of an MBA course lies in an assessment of the curricula, to see whether it is properly tailored to the needs of businesses (Barr and McNeilly, 2002; Dyrud and Worley, 2005; Mintzberg and Gosling, 2002). It is essential for a business school that has developed an MBA course to conduct studies on the course components to ensure that they lead the student to be a good manager (Avison, 2003; Bailey and Ford, 1996; Pinard and Allio, 2005). Without this consideration, there is a chance the MBA program will not meet the needs of businesses, which is particularly important since in the current, dynamic corporate climate, business schools will face increasing competition (Baker and Stowers, 2005; RichardsWilson, 2002).

Even though the development and assessment of MBA curricula is important, it is not easy to achieve, as many obstacles stand in the way. However, if genuine improvement is to be made to an MBA program, the management of the program must overcome these barriers (Hagen et al., 2003; Shelton et al., 2005). Various researchers in the field have elicited the following focuses for business programs:

1. Incorporating case studies into the teaching (Peterson and Pratt, 2004).

2. Adjusting the program to local culture (Rodrigues, 2005).

3. Adding community service courses (Wittmer, 2004).

4. Using outdoor challenge training (Singh and Martin, 2004).

5. Using student-as-client models (Armstrong, 2003).

6. $\quad$ Emphasizing creativity (McIntyre et al., 2003).

7. Including strategy theory and analysis (Greiner et al., 2003).

In order to ensure that MBA programs can meet the needs of the business world, Kleiman and Kass (2007) describe the approaches in developing the MBA curricula by identifying the following three degrees.

\section{The First Degree: Normative MBA}

At this level, the curriculum consists of a core set of courses covering each of the functional areas of business, including finance, marketing, and operations; it also includes analysis tools. This model is widely adopted 
in most business schools (Pfeffer and Fong, 2002; Porter and McKibbon, 1988). However, one problem with this model is the underlying assumption that there is a single management knowledge set that all MBA students should acquire, although in fact businesspeople in different managerial positions and different types of entrepreneurs might need unique skill sets. Many schools have tried to insert additional courses into their MBA programs, but the time limitation means that they cannot teach every subject in-depth; this leaves MBA students with a superficial level of knowledge.

\section{The Second Degree: Reactive Mission-Based MBA}

The second approach was developed by Advanced Collegiate Schools of Business (AACSB, 1991) with the objective of encouraging business schools to design their curricula to achieve specific targets, rather than trying to be everything to everyone. Schools in this level must specify what they want their MBA graduates to be and then create a curriculum that is linked to this goal. As each school will have a different target for its graduates, each MBA program will also have different focuses.

Since the introduction of this idea, business schools have been attempting to rearrange their MBA programs from normative first degree to the second degree by using the following two approaches:

1. Revising missions without significantly changing curricula. This approach may not provide much benefit since the curriculum remains the same. Even though the programs attempt to revise the courses so that they are in line with the mission, the students still need to take the same core subjects. Many students may have already received a foundational understanding of the various business courses in their undergraduate degree and in this case, they must repeat the same topics. As a result, the target mission is not achieved. Moreover, the reforming of the courses to comply with the mission-e.g., focusing on relevant topics - may at times lead the instructors to overemphasize technical details rather than the broad management topics that are most needed.

2. Renovating the course structure according to student needs. In this approach, business schools try to respond to the needs of students and employers. The drawback of this approach is that many times employers have needs that are not appropriate focuses for ideal management education. For example, employers may focus on short-term profitability; in this case, the MBA students will end up focusing primarily on short-term profitability. This has led a number of business schools to revise their courses to emphasize short-term goals, which are not the only skills that a good manager should possess.

The development of MBA curricula in this second degree has many restrictions. For example, when business schools want to eliminate some courses, they need to decide which ones to eliminate and the reason for elimination. Similarly, when they add courses because of employers' needs, are these courses relevant to the organizational mission? Is it appropriate to add or eliminate certain courses to meet employers' needs? Is it appropriate to make educational decisions in order to please the students or employers?

\section{The Third Degree: Proactive Mission-Based MBA}

Here, the development of the MBA curriculum is facilitated by individuals who understand the organization's philosophy and needs, including the needs of other stakeholders. This approach is influenced by human resource development, which consists of the following steps (Noe, 2002, pp. 90-93):

1. Prepare for resistance to change;

2. Devise a clear mission statement;

3. Develop mission-related tasks that graduates are likely to be required to perform;

4. Identify the knowledge, skills, and abilities that graduates must acquire to perform the mission-related tasks;

5. Develop courses that teach the required knowledge, skills, and abilities;

6. Evaluate the success of the new program and make modifications according to the evaluation results. 
The current study uses this approach to evaluate the new MBA curriculum developed by the Faculty of Commerce and Accountancy at Thammasat University and to obtain student opinions towards the current curricula. This research will be conducted using the following methods.

\section{METHODOLOGY}

To evaluate MBA curricula, we collected data from current students in the Faculty of Commerce and Accountancy at Thammasat University, in the MBA and MBA-HRM programs, both of which have similar curricula. The difference between the programs is that the MBA-HRM program focuses on human resource and organizational management. The surveys were completed by the students. The data were collected for two consecutive years, 2009 and 2010, in order to ascertain and assess any differences.

The survey was divided into four parts. In the first part, we collected the personal information of each student. In the second part, respondents were asked for their opinions on the course structure and the appropriateness of the duration of study, using a scale that ranged from 1 (least) to 5 (greatest). The third part contained questions about the benefits of applying the knowledge gained from the whole course of study to their work, including the overall benefit received from the business simulation game. The fourth and final part was a survey on how satisfied the students were with the instructors. The data from the returned surveys are summarized in Table 1 below.

Table 1: Number of Returned Surveys

\begin{tabular}{|l|c|c|c|c|c|c|}
\hline \multirow{2}{*}{ Students in the Programs } & \multicolumn{3}{|c|}{ 2010 Data } & \multicolumn{3}{c|}{ 2009 Data } \\
\cline { 2 - 7 } & Population Size & Sample Size & \% & Population Size & Sample Size & \% \\
\hline MBA50 & & & & 165 & 98 & 59.39 \\
\hline MBA51 $^{1}$ & 162 & 46 & 28.40 & 161 & 91 & 56.52 \\
\hline MBA52 $^{3}$ & 159 & 34 & 21.38 & & & \\
\hline HRM6 $^{4}$ & & & & 28 & 17 & 60.71 \\
\hline HRM7 $^{6}$ & 43 & 35 & 81.40 & 43 & 26 & 60.47 \\
\hline HRM8 $^{6}$ & 24 & 24 & 100.00 & & & \\
\hline Total & 388 & 139 & 35.82 & 397 & 232 & 58.44 \\
\hline
\end{tabular}

Notes: ${ }^{1}$ MBA50 refers to the students in the MBA program, academic year 2007. ${ }^{2}$ MBA51 refers to the students in the MBA program, academic year 2008. ${ }^{3}$ MBA52 refers to the students in the MBA program, academic year $2009 .{ }^{4}$ HRM6 refers to the students in the MBA program with a Concentration on Human Resource and Organization Management, academic year 2007. ${ }^{5}$ HRM7 refers to the students in the MBA program with a Concentration on Human Resource and Organization Management, academic year 2008. ${ }^{6}$ HRM8 refers to the students in the MBA program with a Concentration on Human Resource and Organization Management, academic year 2009.

For the analysis of each curriculum, the study was conducted in the following order:

1. Study and summarize the data collected by using descriptive statistics and complete a preliminary analysis of the data.

2. Analyze the opinions of the students on the curriculum structure and the duration of study.

3. Analyze the opinions of the students on how they can apply the knowledge gained from the course of study to their work and on the overall usefulness of the program.

4. Investigate how to apply the knowledge gained from pre-courses and core courses to work by using factor analysis to see if there are connections between the benefits received from each course and whether the benefits can be extracted as a factor, and if so, how.

5. Study the relationship between the extracted factor from the fourth step and the overall benefits that the students gained by using the correlation and regression analysis to analyze the impact of each factor on how the students apply the knowledge obtained from the program to their work.

\section{RESULTS}

It was found that most respondents were female (61.2\%). The majority of the respondents were 25-27 years of age (49.3\%), and $32.6 \%$ were $28-30$ years. The cumulative GPA of the majority of the respondents (41.6\%) was in the range of 3.25-3.49, and for 33.6\% in the range of 3.5-3.74. Only five students (3.7\%) were unemployed during the period of the program. 
The results show that $78.8 \%$ of the students thought that the total number of credits was "appropriate," up from $68.4 \%$ in the previous year, and $15 \%$ thought that the total number of credits was "too much," down from $26.3 \%$ in the previous year. The majority, or $67.9 \%$ (out of 134 respondents, excluding the missing value), thought that the duration of study was "appropriate," up from $62.8 \%$ in the previous year, and $26.9 \%$ (excluding the missing value) as "too little," down from $32 \%$ in the previous year. Overall, the results indicate that student satisfaction with the curriculum improved. Table 2 shows the ratio of opinions on the appropriateness of total credits and of the duration of study.

Table 2: Ratio of Opinion on Appropriateness of Total Number of Credits and of Program Period

\begin{tabular}{|l|c|c|c|c|c|c|c|c|}
\hline \multirow{3}{*}{ Appropriateness } & \multicolumn{3}{|c|}{ Total Credits } & \multicolumn{3}{c|}{ Duration of Study } \\
\cline { 2 - 10 } & \multicolumn{2}{|c|}{$\mathbf{2 0 1 0}$} & \multicolumn{2}{|c|}{$\mathbf{2 0 0 9}$} & \multicolumn{2}{c|}{$\mathbf{2 0 1 0}$} & \multicolumn{2}{|c|}{$\mathbf{2 0 0 9}$} \\
\cline { 2 - 10 } & Frequency & $\mathbf{\%}$ & Frequency & $\mathbf{\%}$ & Frequency & \% & Frequency & \% \\
\hline Too little & 7 & 6.2 & 11 & 5.3 & 36 & 25.9 & 74 & 32.0 \\
\hline Appropriate & 89 & 78.8 & 143 & 68.4 & 91 & 65.5 & 145 & 62.8 \\
\hline Too much & 17 & 15.0 & 55 & 26.3 & 7 & 5.0 & 12 & 5.2 \\
\hline Total & $\mathbf{1 1 3}$ & $\mathbf{1 0 0 . 0}$ & $\mathbf{2 0 9}$ & $\mathbf{1 0 0 . 0}$ & $\mathbf{1 3 4}$ & $\mathbf{9 6 . 4}$ & $\mathbf{2 3 1}$ & $\mathbf{1 0 0 . 0}$ \\
\hline
\end{tabular}

\section{Applying the Knowledge from All Courses to Benefit Work and the Overall Usefulness of the Program}

We began the investigation of student opinions about the overall usefulness and applicability of the knowledge gained from the program to their work by testing the relationship of the opinion data and the students' personal data. Testing the distribution of usefulness data by grouping according to personal data revealed that the data distribution was not normal. Therefore, we needed to use the chi-square method to test the overall usefulness data. It can be concluded that students' opinions towards the overall usefulness of the program had no correlation with their personal data at the significance level of 0.05 , as shown in Table 3.

Table 3: p-values from the Investigation on the Relationship between Students'

Opinions about the Usefulness of the Program and Their Personal Data

\begin{tabular}{|l|c|}
\hline \multicolumn{1}{|c|}{ Personal Data } & p-value from Chi-Square Testing \\
\hline Program & 0.235 \\
\hline Sex & 0.177 \\
\hline Age & 0.686 \\
\hline Cumulative GPA & 0.267 \\
\hline Working status & 0.367 \\
\hline
\end{tabular}

The results show that the average overall usefulness for the students assessed in year 2010 was 3.79 (out of 5), an increase from 3.74 in 2009. Even though the increase was not significant (p-value $=0.469$ ), it suggested that students in general see benefits from taking the MBA program.

In the study of the relationship between the benefits gained from pre-courses and core courses, data for 2010 and 2009 were grouped together since the data for 2010 were quite small. This was particularly true if only the data of students who completed two years of study (i.e., students of MBA 51 and HRM7) were used-in this case, there would be data from only 63 students. We will combine the data from two years, so that data from students in MBA50, MBA51, HRM6 and HRM7 will be included in this analysis section.

In order to obtain a clearer picture of the components of the curriculum, we analyzed the factors and extracted the particular factors in benefits received from the pre-courses and core courses (in total 19 courses) in the MBA program. First, a preliminary test was done to see if the number of samples was sufficient and appropriate for the factor analysis using the Kaiser-Meyer-Olkin (KMO) measure of sampling adequacy value (Table 4). The value was calculated to be 0.809 , which was higher than the acceptable minimum value of 0.5 . It could thus be concluded that the number of samples was sufficient and appropriate for the factor analysis. Using the Bartlett's test of sphericity value, shown in Table 4 , it was found that the p-value was 0.000 , which was less than the tested value $(\alpha)$ at 0.05 . In conclusion, as all tested variables had linkages with each other, the use of factor analysis was appropriate for this set of data. 
Table 4: Results of KMO and Bartlett's Test in Factor Analysis

\begin{tabular}{|l|c|c|}
\hline \multicolumn{2}{|l|}{} & \multicolumn{2}{|c|}{.809} \\
\hline \multirow{3}{*}{ Baiser-Meyer-Olkin Measure of Sampling Adequacy } & Approx. Chi-Square & 1229.243 \\
\cline { 2 - 3 } & df & 171 \\
\cline { 2 - 3 } & Sig. & .000 \\
\hline
\end{tabular}

The next step was to extract the factors with correlation by using principle component analysis and factor rotation by varimax with the Kaiser normalization method. It was found that there were five extracted factors that could explain the deviation of the total variables at $62.705 \%$ of the total deviation. This implies that these extracted factors are credible. follows.

From the factor analysis, we were able to group all 19 pre-courses and core courses into five groups as

Factor 1: Economics and Finance
BA. $601 \quad$ Managerial Economics
BA. 602 Macro Economic Indicators and Business Decisions
BA. 611 Accounting for Decision Making
BA. 621 Financial Management

Factor 2: Strategies and Business Model
BA. 501
Business Models and Processes
BA. 631
Marketing Management
BA. 701
Performance Management and Value Creation
BA. 702
Seminar in Contemporary Strategic Management
BA. 703/704 Independent Study

Factor 3: Relationship within Organization
BA. 504
Business Communication Skills
BA. 603
Organizational Behavior
BA. 641
Human Resource Management
BA. 642
Leadership and Change

Factor 4: Management Analytical Tools
BA. 502
Business Statistics
BA. 503
Quantitative Analysis
BA. 651
Logistics and Operations Management

Factor 5: Sustainable Development
BA. 604
Business Research
BA. 605
Innovative Creation for Competitive Advantage
BA. 606
Corporate Governance and Social Responsibility

Details of the analysis results are displayed in Table 5.

After performing the factor analysis and obtaining five factors, we analyzed the regression by defining the overall benefits gained from the program as the dependent variable and all five factors that were extracted from the factor analysis as independent variables, by adopting the multiple regression method in the SPSS program. It was found that all five independent variables were able to explain the overall benefits gained from the program with $R^{2}=$ 0.516 and adjusted $R^{2}=0.500$. This demonstrates that all five factors were able to explain the overall usefulness correctly by $50 \%$, which is considered a moderate level. Table 6 shows the multiple regression analysis results. 
Table 5: Coefficient of Variables for the Factors Extracted from Component Analysis by Rotation with Varimax Method

\begin{tabular}{|c|c|c|c|c|c|}
\hline . & \multicolumn{5}{|c|}{ Component } \\
\hline & 1 & 2 & 3 & 4 & 5 \\
\hline BA621 & .858 & & & .160 & .193 \\
\hline BA611 & .811 & & & .130 & .227 \\
\hline BA601 & .657 & .355 & .142 & .266 & \\
\hline BA602 & .642 & .285 & .230 & .134 & -.154 \\
\hline BA501 & & .727 & .201 & .181 & \\
\hline BA631 & .332 & .662 & & .129 & .211 \\
\hline BA702 & .227 & .632 & .117 & & .270 \\
\hline BA701 & .117 & .527 & .180 & .350 & .187 \\
\hline BA703/704 & .196 & .470 & .110 & .121 & .374 \\
\hline BA603 & .210 & & .812 & .150 & \\
\hline BA641 & & .221 & .713 & .128 & .219 \\
\hline BA642 & & .247 & .699 & & .195 \\
\hline BA504 & & & .618 & & .156 \\
\hline BA502 & .166 & .108 & & .848 & .185 \\
\hline BA503 & .248 & .127 & & .813 & .107 \\
\hline BA651 & .310 & .438 & .232 & .534 & \\
\hline BA606 & & & .366 & & .743 \\
\hline BA605 & .105 & .334 & .276 & & .654 \\
\hline BA604 & & .151 & & .439 & .602 \\
\hline
\end{tabular}

Notes: Extraction method: principal component analysis. Rotation Method: varimax with Kaiser normalization. a. Rotation converged in 7 iterations.

Table 6: Multiple Regression ${ }^{1}$ Analysis Results

\begin{tabular}{|l|c|c|}
\hline \multicolumn{1}{|c|}{ Variable } & Coefficient & p-value \\
\hline Factor 2. Strategies and Business Model & 0.306 & .000 \\
\hline Factor 1. Economics and Finance & 0.234 & .000 \\
\hline Factor 5. Sustainable Development & 0.182 & .000 \\
\hline Factor 4. Management Analytical Tools & 0.162 & .000 \\
\hline Factor 3. Relationship within Organization & 0.128 & .001 \\
\hline
\end{tabular}

\section{CONCLUSION}

This study found that the overall usefulness of knowledge gained by MBA students can be explained by the usefulness of all five course groups extracted from pre-courses and core courses. These five groups are able to explain $50 \%$ or half of the overall usefulness. The rest should be explained by the elective subjects that cannot function as the extracted factors because MBA students can select different courses based on their interests. As for the students from the MBA-HRM program, even though they have common elective courses, the amount of data is not sufficient for factor extraction.

The regression equation yielded that students paid the most attention to courses in the "Strategies and Business Model" group. This is observed from the coefficient of Factor 2 in the highest equation. This group of courses will help the students to understand how to successfully manage the business process. The second most important factor is Factor 1, "Economics and Finance," which is the group of courses that will help the students to understand the economic environment that influences business success. The third in importance is Factor 5,

\footnotetext{
${ }^{1}$ An assumption test of multiple regression for residual analysis was conducted. It was found that the results conformed to the
} regression assumptions. 
"Sustainable Development," which is required to continue business success. The next in line is Factor 4, "Management Analytical Tools," which is essential for business analysis and decision making. The last factor is Factor 3, "Relationship within Organization," in which students learn to understand the various relationships within the organization.

The analysis indicates that the MBA program run by the Faculty of Commerce and Accountancy at Thammasat University, for which the curriculum (including both pre-courses and core courses) was redesigned in 2006, is useful to students in their professional lives. This information is not only useful for Thammasat University, but will also be beneficial to administrators from other educational institutes that would like to improve their MBA programs by aligning them with the student need to apply the knowledge gained in the programs to future work. This research does, however, have limitations in that it focused on the usefulness of knowledge from only the point of view of current students. Further research could be carried out in the future to study the usefulness of knowledge from other points of view, such as the point of view of employers or students who have been out of university for a certain amount of time. This will deepen our understanding of MBA programs and allow administrators to design programs that produce qualified managers and thus aid the development of the country.

\section{ACKNOWLEDGEMENT}

This study received a research grant from the Faculty of Commerce and Accountancy, Thammasat University.

\section{AUTHOR INFORMATION}

Associate Professor Sripen Supmonchai obtained Bachelor Degree in Business Administration ( $1^{\text {st }}$ Class Honor) and Master of Business Administration from Thammasat University, Thailand and Master of Business Administration (with Distinction) from New York University, US. She has extensive experience in both public and private sectors. Her specialization is in operations management, service management, and project management. She also published textbook in Business Statistics and Business Research. E-mail: sripen@tu.ac.th

Associate Professor Dr. Nopadol Rompho joined the Thammasat Business School in 2003 as a lecturer at Department of Operations Management. His main research interest is in the area of performance measurement and operations management. Before joining the university, he used to work in oil and gas companies as an engineer and business analyst. He obtained a Bachelor's degree in Chemical Engineering $\left(2^{\text {nd }}\right.$ Class Honor) from Chulalongkorn University, Thailand, Master of Science in Chemical Engineering from Oregon State University, US, Master of Business Administration from Thammasat University, Thailand, and Doctor of Philosophy from University of Glasgow, U.K. E-mail: nopadol@tbs.tu.ac.th (Corresponding author)

\section{REFERENCES}

1. Armstrong, M. J. (2003). Students as clients: A professional services model for business. Academy of Management Learning \& Education, 2, 371-375.

2. Association to Advance Collegiate Schools of Business (1991). Standards for business and accounting accreditation. St. Louise, MO: Author.

3. Avison, D. (2003). Information systems in the MBA curriculum: An international perspective. Communications of AIS 2003, 11, 117-128.

4. Bailey, J. and Ford, C. (1996). Management as a science versus management in practice in postgraduate business education. Business Strategy Review, 7, 7-12.

5. Barker, R. T. and Stowers, R. H. (2005). Learning from our students: Teaching strategies for MBA professors. Business Communication Quarterly, 68, 481-487.

6. Barr, T. F. and McNeilly, K. M. (2002). The value of students' classroom experiences from the eyes of the recruiter: Information, implications, and recommendations for marketing educators. Journal of Marketing Education, 24, 168-174.

7. Carmichael, T. and Sutherland, M. (2005). A holistic framework for the perceived return on investment in an MBA. South African Journal of Business Management, 36, 57-70. 
8. Connolly, M. (2003). The end of the MBA as we know it? Academy of Management Learning and Education, 2, 365-371.

9. Dyrud, M. A. and Worley, R. B. (2005). Teaching MBAs, part 1. Business Communication Quarterly, 68, 479-480.

10. Goodwin P. and Wright G. (2004). Decision Analysis for Management Judgement. John Wiley \& Sons, Ltd.

11. Greiner, L. E., Bhambri, A., and Cummings, T. G. (2003). Searching for a strategy to teach strategy. Academy of Management Learning \& Education, 2, 402-421.

12. Groebnor D. F., Shannon P. W., Fry P. C., and Smith K. D. (2008). Business Statistics A Decision-Making Approach. Pearson Education, Inc.

13. Hagen, R., Miller, S., and Johnson, M. (2003). The disruptive consequences of introducing a critical management perspective into an MBA program. Management Learning, 34, 241-258.

14. Kleiman, L. S. and Kass, D. (2007). Giving MBA programs the third degree. Journal of Management Education, 31, 1, 81-103.

15. McIntyre, F. S., Hite, R. E., and Rickard, M. K. (2003). Individual characteristics and creativity in the marketing classroom: Exploratory insights. Journal of Marketing Education, 25, 143-150.

16. Mintzberg, H. and Gosling, J. (2002). Reality programming for MBAs. Strategy and Business, 26, $28-31$.

17. Noe, R. A. (2002). Employee training \& development ( $2^{\text {nd }}$ ed.). Boston: McGraw-Hill.

18. Peterson, R. and Pratt, E. (2004). The history sphere in MBA marketing instruction: An application. Marketing Education Review, 14, 55-68.

19. Peterson, R. T. (2006). Futurism: Its potential and actual role in master of business administration (MBA) education. Journal of Education for Business, 81, 6, 334-342.

20. Pfeffer, J. and Fong, C. T. (2002). The end of business schools? Less success than meets the eye. Academy of Management Learning and Education, 1, 78-95.

21. Pinard, C. and Allio, M. (2005). Innovations in the classroom: Improving the creativity of MBA students. Strategy \& Leadership, 33, 49-51.

22. Porter, L. W. and McKibbon, L. E. (1998). Management education and development: Drift or thrust into the $21^{\text {st }}$ century. New York: McGraw-Hill.

23. Rodrigues, C. A. (2005). Culture as a determinant of the importance level business students place on ten teaching/learning techniques: A survey of university students. Journal of Management Development, 24, 608-621.

24. Shelton, C., Yang, J., and Qian, L. (2005). Managing in an age of complexity; quantum skills for the new millennium. International Journal of Human Resource Development \& Management, 5, 127-141.

25. Singh, P. and Martin, L. R. (2004). Accelerated degree programs: Assessing student attitudes and intentions. Journal of Education for Business, 79, 299-306.

26. Van Auken, S. and Chrysler, E. (2005). The relative value of skills, knowledge, and teaching methods in explaining master of business administration (MBA) program return on investment. Journal of Education for Business, 81, 41-45.

27. VanderMey, A. (2009). MBA Job Outlook Dims. Bloomberg Businessweek. Retrieved from: http://www.businessweek.com/bschools/content/feb2009/bs2009022_191866.htm\#r=auth-s

28. Wittmer, D. P. (2004). Business and community: Integrating service learning in graduate business education. Journal of Business Ethics, 51, 359-372. 
NOTES 